Seventh draft. Please do not cite or quote.

\title{
Valuing Congestion Costs in the British Museum
}

By David Maddison and Terry Foster

\footnotetext{
${ }^{1}$ The authors are with the Centre for Cultural Economics and Management and Goldman Sachs respectively. The assistance of the British Museum is acknowledged but it is emphasised that the work was not commissioned by the British Museum and the views that it contains are those of the authors only. The authors are grateful to David Pearce, Brett Day and Peter Johnson for helpful comments on an earlier version of this paper.
} 
Seventh draft. Please do not cite or quote.

Valuing Congestion Costs in the British Museum 


\begin{abstract}
Museums are potentially congestible resources because the exhibits they contain are, in any relevant sense of the word, irreproducible. Insofar as visitor congestion diminishes the value of individuals' visits it constitutes an additional reason for charging for admission to museums, albeit one not previously considered. A policy of free access to a museum containing unique treasures may dissipate the economic benefits of the museum.

Within the context of an empirical study undertaken for the British Museum using stated preference techniques it is shown that the congestion cost posed by the marginal visitor is quite high. Notwithstanding the argument that visits to the museum may possess external benefits, this points to the desirability of instigating charges for admission. Furthermore, it is shown that the marginal congestion cost decreases at least over a range as visitor numbers increase. In other words beyond certain levels introducing more visitors does not worsen congestion. This suggests that, contrary to what is often assumed, charging more during periods of high demand may be undesirable.

Insofar as congestion is a widespread phenomenon in important museums, galleries and sites of historical heritage the issues raised in this paper as well as the methodology devised to determine congestion costs could have widespread application.
\end{abstract}




\section{Introduction}

The British Museum in Bloomsbury in London, one of the greatest museums in the world, was founded by Act of Parliament in 1753. Originally comprising the collections of Sir Hans Sloane and the Halerian collection of manuscripts, the museum was first opened to the public in 1759 . Today the museum is largely funded by a Government grant with additional income secured through sponsorship and a wide range of commercial and other fund raising activities. The collections of the museum are at the time of writing held in ten departments: Coins and Medals; Egyptian Antiquities; Ethnography; Greek and Roman Antiquities; Japanese Antiquities; Mediaeval and Later Antiquities; Oriental Antiquities; Prehistoric and Romano-British Antiquities; Prints and Drawings; and Western Asiatic Antiquities.

Apart from a brief period in the early 1970s, admission to the British Museum has always been free to visitors (although a charge is sometimes made for temporary collections). The official attendance figure for the museum in 1999 stood at 5.4 million visitors. Unfortunately, the large number of visitors that the museum attracts can adversely affect the quality of the experience that it provides. Overcrowding results in queuing, noise, occasional shoving and ultimately in an inability to view the exhibits. But congestion may mean far more than the close physical proximity of other people. It may be that viewing exhibits is a pastime enjoyed most of all without any intervening-distraction caused by the presence of other people. So even on days when there are relatively few visitors, there may still be an external cost imposed by visitors on each other 2 . The possibility of increased attendance leading to congestion and disagreeable visiting conditions such that that overall benefit actually declines is also acknowledged by those with expertise in museum management (see for example Cannon-Brookes 2001).

The objective of this study is to value the congestion costs imposed by visitors to the British Museum on their fellows. This is achieved by means a stated preference questionnaire in which a random sample of visitors to the British Museum were invited to choose between alternative scenarios described by different levels of admission charges and differing degrees of congestion. An important advantage of the method used is that it does not artificially limit the reasons why individuals dislike congestion. This paper represents a first attempt to devise a methodology for exploring these issues and the technique may be applicable to any site under pressure from mass visitation.

There is an existing literature that is tangential to this paper. The seminal paper of Peacock and Godfrey (1974) sets the stage for thinking about museums from an

\footnotetext{
${ }^{2}$ By contrast it is possible to imagine experiences which are actually improved by the presence of other people such as sporting events and music festivals. It is also clear that congestion is not a terribly important phenomenon for the majority of museums. At the same time anyone who has visited the Tate Modern will realise that its levels of congestion match those in the British Museum.
} 
economics perspective with the museum as a firm producing an unusual type of product and with specialised labour and the exhibits themselves as the inputs. The issue of congestion costs has of course been fully explored in the context of road transport (see for example Newbery 1992). Elsewhere economic valuation techniques have been applied to cultural issues in the United Kingdom (see Forrest et al 2000). There are however no examples of such valuation techniques being applied to congestion, nor even of use of the technique to value access to museums in the United Kingdom although see Martin 1994 for the only published attempt to determine the total economic value of a museum (located in Quebec).

The remainder of the paper is organised as follows. The next section considers arguments for and against charging for access to museums. The third section develops a methodology for empirically determining the extent of congestion costs in the context of a museum. In section four issues related to the empirical implementation of the model are discussed. In section five the results of the survey are econometrically analysed and in section six the results discussed. The final section concludes. 


\section{Arguments for and against charging for admission to museums}

Charging for admission to museums is extraordinarily controversial, perhaps even more so than the pricing of roads. Historically entrance to museums in Britain has been free but now between 48 and 58 percent of them charge for admission (see Creigh-Tyte and Selwood 1998). Remaining true to their founding principles the trustees of the British Museum have always been implacably opposed to charging. Beginning with the distributional ones, we now consider the arguments for and against subsidising admission to museums. But before doing so it is important to emphasise what follows are arguments for and against subsidising visits to museums and not arguments for subsidising museums. This distinction follows from the multiple functions that museums are argued to perform: providing opportunities for recreation and education, and maintaining collections as a necessary component of nationhood. The latter is a pure public good and the theoretical case for subsidising pure public goods is clear-cut ${ }^{3}$.

What evidence there is suggests that those people who visit museums draw predominantly from the higher social classes. This immediately suggests that the practice of subsidising visits to the museums is favourable to the rich and hardly likely to be an effective way of transferring welfare to poorer people. It appears therefore to be very difficult to construct an argument for subsidising museum visits on distributional grounds and we therefore turn to arguments based on notions of economic efficiencyt.

The argument heard most often in favour of the continuation of free entry is that the marginal costs of admission to museums are zero. With zero marginal costs of admission economic efficiency would imply a zero admission charge. This argument is overused since additional visitors do indeed impose costs in terms of the security, maintenance and upkeep. It is also, as we shall soon see, incomplete in that it considers only those costs borne by the museum itself. Furthermore the required subsidies require to be raised through distortionary taxes. In any event, whilst it may be true that the marginal costs of visiting a museum are below the average cost of visiting a museum, this would imply a subsidy for economic efficiency not a zero admission price (see Bailey and Falconer 1998).

There is an argument that efforts at revenue raising do not result in additional overall revenues because the revenues gained are offset to some extent by reductions in government grants and donations from benefactors and visitors. If this is the case then there is an incentive for museums not to charge (Anderson 1998). Furthermore under a regime of charging museum curators would then be obliged to mount only populist 'impressionist' exhibitions to the detriment of the education of the visitors. Whether this is in fact detrimental or beneficial is highly contentious. It is sometimes

\footnotetext{
${ }^{3}$ There is however no evidence on the extent to which individuals are willing to pay in order to maintain collections of uncertain composition that they are not allowed to visit.

${ }^{4}$ One could easily turn this argument around by saying that the characteristics of museum visitors make it desirable to charge for admission to museums.
} 
suggested that high transactions-costs mean that it is inefficient to charge for entry. This argument may have some relevance when the dead-weight losses from congestion costs are less than the resource costs of collecting the admission charges.

Possibly the most respectable argument for the retention of free admissions is the possible existence of positive externalities from such visits (see for example Robbins, 1971). Whether this is the case or not is an unresolved empirical matter. Of course the presence of external benefits does not in itself represent an argument for free admission, rather it represents an argument in favour of the subsidisation of visits to the extent that additional subsidies provide benefits at the margin. Some would say that there 'external benefits' in terms of the effects of the museum on the hotels and other businesses in the proximity of museums that benefit from the free admission policy of museums. This is undoubtedly true but these are not an external benefit so much as a pecuniary benefit. Pecuniary benefits arising from a policy of free admission may be of concern if the goal is economic regeneration

A major argument in favour of charging for museums is that large fractions of the visitors will be from abroad. Insofar as the government cares only about the welfare of its own citizens then it would wish to see free entry for them and profit maximising charges for the foreigners. Price discrimination on the basis of nationality is typically not possible but may be a sensible strategy for museums in less developed countries to pursue, especially where there is a large disparity between the incomes of local people and those of foreign tourists. The imposition of charges for foreign visits represents, according to some, an almost unanswerable case for charging (see for example O'Hagan 1995) especially when it is considered that foreign visitors have paid almost nothing for the general upkeep of the museum.

However, the main argument in favour of charging for museums is one that has so far received little if any attention, namely the need to prevent overcrowding . The basic problem is that, whilst individuals might make some ex-ante assessment of the likely crowds before deciding whether or not to go to the museum, no visitor rationally takes account of the congestion that their visit might imposes upon others. In such a situation a charge is appropriate in order to confront individuals with the congestion cost that their presence imposes upon others. This charge would depend upon the level of demand and might vary considerably with the season. If it is taken at face value, a policy of promoting 'access for the many rather than for the few' collides headlong with the proposition that the contents of museums are congestible resources and that congestion might diminish the value of the experience to the visitor.

\footnotetext{
${ }^{5}$ The scale of congestion costs uncovered in this paper is such that the resource cost of collecting the admission charges do not appear to be prohibitive.

${ }^{6}$ Obviously this is not a reason for subsidising visits to the British Museum given that it is located in Bloomsbury in Central London.

${ }^{7}$ Peacock and Godfrey (1974) mention the possibility of congestion in museums and galleries but do not discuss it.
} 
In transport economics the existence of high congestion costs points to the inadequacy of transport infrastructure and suggests that the transport infrastructure should be expanded. In the case of museums however there is doubt concerning the extent to which increasing floor space could in fact alleviate congestion. The reason is that the museum exhibits are, in any relevant sense, irreproducible. Increasing floor space cannot reduce congestion because only the space around the exhibits matters although increasing opening hours might ${ }^{-}$. For this reason congestion costs are likely to be an irreducible component of the cost of visiting museums. Yet surprisingly the argument that congestion costs are significant and represent an important reason why the most popular museums should charge has not received any attention in the literature ${ }^{9}$.

Apart from charging, in the long term one solution to the problem of congestion in museums might be to expand the museum in the sense of displaying more exhibits; another to use the internet to allow individuals to experience a 'virtual' tour of the museum. These are however unlikely to eliminate entirely congestion costs. Even if the museum has additional items in its collection these are unlikely to be as fine as those already selected for display 10 . A virtual tour of a museum may not yield the same satisfaction as physical visit. And both imply additional costs in terms of floor space and technology that might outweigh the benefits of reduced congestion. Other means of tackling congestion costs have much less to recommend them. The idea of simply placing a limit on the number of people allowed into a museum or gallery risks excluding individuals with a very high value for visiting the museum whilst those with low values might be allowed in. Here is an obvious inefficiency that using price to limit access does not suffer from 11 .

\footnotetext{
${ }^{8}$ Note however that the British Museum is already open every day of the year apart from Christmas Day, Boxing Day, New Year's Day and Easter Day.

${ }^{9}$ See Johnson and Thomas (1998) for a review of outstanding research issues in the economics of museums.

${ }^{10}$ Most museums only ever display a fraction of their collections (see Frey 1994 for a discussion of this phenomenon).

${ }^{11}$ There may also be scope for a charging structure that has high prices at some times in the week to cater for those who are willing to pay more for a quiet atmosphere and low prices at other times for those indifferent to the crowds. Selling cheaper tickets permitting the holder to visit the museum for a fixed number of hours might also be able to increase welfare (although it is perhaps harder to implement). For a discussion of the pricing policies and opening hours of museums see Frey (1994).
} 


\section{The Theoretical Model}

The theoretical model used to infer the value of congestion experienced by visitors to the British Museum is based on the utility difference approach associated with Hanemann (1984) and Sellar et al (1986).

The simplest possible representation of museum visitors' indirect utility function is the linear indirect utility function:

$$
U^{0}=\beta Y+\alpha_{1} Q^{0}+\alpha_{2}\left(Q^{0}\right)^{2}+\alpha_{3} Q^{0} X_{1}+\alpha_{4} Q^{0} X_{2}+\ldots+\eta^{0}
$$

where $\mathrm{U}$ is utility, $\mathrm{Y}$ is income, $\mathrm{Q}$ is the level of congestion, $\mathrm{X}$ represents a vector of socio-economic characteristics and $\alpha$ and $\beta$ are unknown parameters. The idiosyncratic error term is given by $\eta$. The superscript 0 indicates that the current congestion level being considered is the one associated with free entry. Utility in the scenario in which individuals are charged an amount $\mathrm{P}$ for admission is given by:

$$
U^{1}=\beta(Y-P)+\alpha_{1} Q^{1}+\alpha_{2}\left(Q^{1}\right)^{2}+\alpha_{3} Q^{1} X_{1}+\alpha_{4} Q^{1} X_{2}+\ldots+\eta^{1}
$$

in which the superscript 1 indicates a changed level of utility and lower level of congestion. In either indirect utility function the price of other goods and services are assumed fixed. The parameter $\beta$ can be interpreted as the marginal utility of income and is clearly constant in this formulation. The higher order term in Q permits marginal willingness to pay to vary with the level of congestion. Note also that this utility is assumed to be dependent on a number of socio-economic characteristics denoted by X. The willingness to pay (WTP) for a reduction in the level of congestion from $\mathrm{Q}^{0}$ to $\mathrm{Q}^{1}$ is:

$$
W T P=\frac{\alpha_{1} \Delta Q+\alpha_{2} \Delta\left(Q^{2}\right)+\alpha_{3} \Delta Q X_{1}+\alpha_{4} \Delta Q X_{2}+\ldots+\mathcal{E}}{\beta}
$$

where $\varepsilon=\eta^{0}-\eta^{0}$ and $\Delta$ is the difference operator. An alternative yet equally tractable model is the log linear formulation in which utility is assumed to be a logarithmic function of income. The characteristic of this representation of the utility function is that the willingness to pay for a change in the characteristic is proportionate to income. We have:

$U^{0}=\beta \log Y+\alpha_{1} Q^{0}+\alpha_{2}\left(Q^{0}\right)^{2}+\alpha_{3} Q^{0} X_{1}+\alpha_{4} Q^{0} X_{2}+\ldots+\eta^{0}$

in the high congestion zero entry price scenario and in the low congestion positive entry price scenario:

$U^{1}=\beta \log (Y-P)+\alpha_{1} Q^{1}+\alpha_{2}\left(Q^{1}\right)^{2}+\alpha_{3} Q^{1} X_{1}+\alpha_{4} Q^{1} X_{2}+\ldots+\eta^{1}$ 
WTP to move from $\mathrm{Q}^{0}$ to $\mathrm{Q}^{1}$ is given by:

$W T P=Y\left[1-\exp \frac{-\alpha_{1} \Delta Q-\alpha_{2} \Delta\left(Q^{2}\right)-\alpha_{3} \Delta Q X_{1}-\alpha_{4} \Delta Q X_{2}-\ldots-\varepsilon}{\beta}\right]$

and $\varepsilon$ is as before. Both the linear and log linear specifications are of course nested within a more general Box Cox model of utility. The change in utility associated with the change in congestion levels is given by:

$\Delta U=\beta P+\alpha_{1} \Delta Q+\alpha_{2} \Delta\left(Q^{2}\right)+\alpha_{3} \Delta Q X_{1}+\alpha_{4} \Delta Q X_{2}+\ldots+\varepsilon$

for the linear utility model. For the logarithmic utility model it is given by:

$\Delta U=\beta[\log Y-\log (Y-P)]+\alpha_{1} \Delta Q+\alpha_{2} \Delta\left(Q^{2}\right)+\alpha_{3} \Delta Q X_{1}+\alpha_{4} \Delta Q X_{2}+\ldots+\varepsilon$

The individual is assumed to inform the researcher whether the proposed reduction in congestion and associated increase in entry prices represents an improvement in welfare. The probability $\mathrm{p}$ that the individual will report that this constitutes an improvement is given by:

$p=F[\Delta U ; \alpha, \beta]$

where $\mathrm{F}$ is the cumulative density function. The probability $(1-\mathrm{p})$ that the individual will report that this constitutes a reduction in their utility is given by:

$1-p=1-F[\Delta U ; \alpha, \beta]$

The parameters of the model are derived using maximum likelihood techniques. In either case it is assumed that the difference in wility is a logistically distributed random variable with zero mean and unit variance $e^{12}$. The discussion now turns to the empirical implementation of this model.

\footnotetext{
${ }^{12}$ In common with virtually all other researchers we do not impose any restriction that prevents willingness to pay being negative and willingness to pay exceeding annual income. The reason for this is that, for most people, visiting the British Museum will be a once in a lifetime rather than an annual event. Similarly there is no a priori reason to suppose that everyone prefers less congestion to more.
} 


\section{Empirical Implementation}

Perhaps the most challenging issue is how best to present the alternative congestion scenarios. One possibility - asking individuals directly how much they would be prepared to pay in terms of visitor numbers - was quickly ruled out. Visitor numbers by themselves are meaningless. The only possible means of conveying alternative congestion scenarios involves the use of photographs taken within the museum. The problem is that visitor numbers fluctuate quite considerably throughout the day as people enter and leave the museum. Even taking photographs at the same location and at the same time of day would result in quite different appearance given the random arrival and departure of groups of people at particular points in the museum. One cannot arrive at the museum, take a photograph, and claim that it represents the congestion level associated with however many individuals visited the museum on that day.

The protocol for attributing to the photographs a particular level of congestion was as follows. A series of photographs were taken from precisely the same location at the same angle at two-hour intervals over consecutive days. The photographs were then ordered on the basis of the number of individuals appearing in each photograph. The photograph with the median number of individuals appearing in it was declared to be representative of congestion during the period over which the photographs were taken. The photographs showing the greatest number of individuals was taken as the 'High Congestion' scenario and the photographs showing the least number of individuals was declared to be the 'Low Congestion' scenario. This whole process was repeated at three different locations throughout the museum and involved taking a considerable number of photographs. The geometric mean was taken for each scenario and the resulting photographs were assembled in a photomontage.

An example might help to clarify the procedure employed. The median number of individuals appearing in the frame of the photograph taken of the Greek Bronze Age gallery was 20 . The maximum number of people counted in any one photograph was 36 and the minimum number of people was 11 . These figures are shown in table 1 . The photographs taken in the Egyptian gallery showed a median count of 19 people, a maximum of 25 and a minimum of 13 . The West Stairs had a median number of 25 and a maximum of 36 and a minimum of 5 . The geometric mean of the rows is given in the fifth column. Average congestion levels are associated with a geometric mean of 21.2. This in turn is associated with daily visitor numbers of 18,737 (the average for July when these pictures were taken). The High Congestion scenario on the other hand shows a geometric mean of 31.9. This is associated with daily visitor numbers of $28,194(=18,737 \times 31.9 / 21.2)$ people. The Low Congestion scenario shows a geometric mean of 8.9 corresponding to $7,866(=18.737 \times 8.9 / 21.2)$ people.

Of course there is a risk that the photographs chosen were taken in locations that are in some way unrepresentative of the general situation within the museum. In order to 
check this possibility a second set of photographs was taken illustrating the situation at the Main Entrance, the Main Stairs and the China and Southeast Asia gallery in order to form a comparison.

Each choice-experiment involved the individual making a comparison between alternative scenarios distinguished by the level of congestion in the British Museum and the existence of an entry charge. The respondent was shown two photomontages. The first photomontage showed three different locations suffering from a high degree of congestion. The second photomontage showed the same three locations suffering from somewhat less congestion. The respondent was then informed that the photomontage showing the higher level of congestion corresponded to the current policy of free admission. The photomontage showing a lower level of congestion was on the other hand said to be the outcome of charging for admission. Charges of $£ 3$, $£ 6, £ 12$ and $£ 20$ were randomly chosen. The upper bound was suggested by the pilot survey as almost all individuals refused to pay $£ 20$. Thus the respondent was forced to make a choice between free entry with high levels of congestion or lower levels of congestion but being charged for entry. Each individual was presented with two different choice experiments in which the difference in congestion levels varied.

Note that in order to make the choice-experiment acceptable to respondents it was suggested that these charges would be applied only to persons aged 16 or above. The need to do this is in itself an interesting finding suggesting that individuals might see potential benefits for society in the visits of young people.

It is of course possible to ask individuals to select their preferred alternative from more than two alternatives and even possible to ask individuals to rank the alternatives (see for example Beggs et al, 1981). There is however concern about the increasing burden that this might place upon the cognitive ability of respondents and the implications of the strategies that individuals might adopt to simplify the complexity of the task presented to them. Therefore the nature of the experiment presented to the respondents was deliberately kept as simple as possible. In order to avoid the choice appearing purely hypothetical in each choice-experiment one of the options always involved free-admission.

A final concern was that rather than basing their decisions on the photomontages presented to them, respondents might base their decisions on their own experiences gained during their current visit. In order to test for this effect individuals were questioned on their way into the museum as well as on their way out. 
Table 1: The Congestion Scenarios

First Set of Photographs:

$\begin{array}{llllll} & \text { Greek } & \text { Egyptian } & \begin{array}{l}\text { West } \\ \text { Stairs }\end{array} & \begin{array}{l}\text { Geometric } \\ \text { Mean }\end{array} & \begin{array}{l}\text { Daily } \\ \text { Visitors }\end{array} \\ \text { High Congestion } & 36 & 25 & 36 & 31.9 & 28,194 \\ \text { Average Congestion } & 20 & 19 & 25 & 21.2 & 18,737 \\ \text { Low Congestion } & 11 & 13 & 5 & 8.9 & 7,866\end{array}$

Second Set of Photographs:

\begin{tabular}{|c|c|c|c|c|c|}
\hline & $\begin{array}{l}\text { Main } \\
\text { Entrance }\end{array}$ & $\begin{array}{l}\text { Main } \\
\text { Stairs }\end{array}$ & Asia & $\begin{array}{l}\text { Geometric } \\
\text { Mean }\end{array}$ & $\begin{array}{l}\text { Daily } \\
\text { Visitors }\end{array}$ \\
\hline High Congestion & 17 & 49 & 25 & 27.5 & 25,763 \\
\hline Average Congestion & 14 & 30 & 19 & 20.0 & 18,737 \\
\hline Low Congestion & 4 & 23 & 13 & 10.6 & 9,931 \\
\hline
\end{tabular}

Source: Own calculations. 


\section{Description of the survey}

The survey instrument went through a number of design phases including focus group analysis and a pilot survey prior to the main survey. The final survey was divided into three sections. In the first section individuals were asked about their current use of and attitudes towards the British Museum. The second section dealt with the valuation of congestion externalities via choice-experiments. The third section collected information on respondents' socio-economic characteristics (chiefly their age, sex, family size, level of education and country of residence). The survey was conducted by means of face to face interviews with individuals entering and leaving the British Museum. Individuals were recruited at random without being informed about the purpose of the survey. In total 400 individuals were interviewed during August 2000 13 .

Attention should be drawn to one important shortcoming of the sampling of individuals entering and leaving the museum. This was the fact that the interviews were conducted only in English. This might have been expected to lead to an over representation of individuals from Britain, North America and other English speaking countries at the expense of those from South East Asia and Japan. This is a frequent problem with studies of sites with an international focus. In fact however the percentage of visitors from the United Kingdom included in the very sample (27 percent) is almost identical to the 25 percent cited on the British Museum's web-

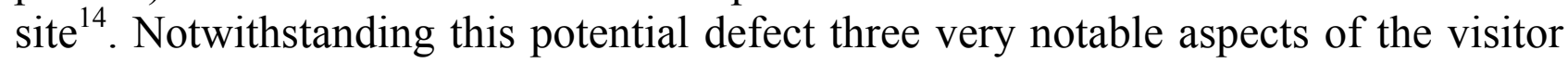
profile are that the visitors to the museum are extremely highly educated, have after tax household incomes that are far higher than average and are more often than not, from abroad.

\footnotetext{
${ }^{13}$ The interviews were completed prior to the opening of the Great Court: a large covered courtyard whose construction was financed by grants from the Millennium Commission and the Heritage Lottery fund. One might suppose that the opening of the Great Court in December 2000 would reduce congestion costs in British Museum. Once in the Great Court the visitor can choose from a number of entry points into the different galleries. On the other hand there is no additional space for exhibits and the space around the museum's most popular exhibits is unchanged. Furthermore some individuals who might not have come to the museum before may now wish to visit. This actually seems to have occurred with visits in the first month following the opening of the Great Court being 40 percent than the corresponding period last year.

${ }^{14}$ The web-site address is $<$ http://www.thebritishmuseum.ac.uk/corporate/stats.html $>$. There do not appear to be any other records of visitor characteristics that would help determine how representative our sample is. The British Museum itself conducts an infrequent visitor survey but does not release the results.
} 
Table 2: Definition of the variables

Variable Definition

PRICE Price paid for admission (£s)

$\Delta$ VISITORS Difference in daily visitor numbers offered to the respondent (thousands)

INCOME After tax household income (£s)

DEGREE Takes the value unity if the respondent has a degree, a higher degree or professional equivalent, zero otherwise

MALE Takes the value unity if the respondent is male, zero otherwise

AGE Age of respondent (years)

FAMILY Size of respondent's household

UK Takes the value unity if the respondent is a UK resident, zero otherwise

ALTPHOTO Takes the value unity if the second alternative set of photos is used, zero otherwise

OUT Takes the value unity if the respondent is questioned after their visit, zero otherwise

Source: Own calculations. 
Table 3: Description of the data

$\begin{array}{lllll} & \text { Mean } & \text { Standard Dev. } & \text { Maximum } & \text { Minimum } \\ \text { PRICE } & 10.25 & 6.499254 & 3 & 20 \\ \Delta \text { VISITORS } & 13.16075 & 5.243936 & 7.026 & 20.328 \\ \text { INCOME } & 41745.74 & 42193.75 & 2500 & 400000 \\ \text { DEGREE } & 0.8075 & 0.3945102 & 0 & 1 \\ \text { MALE } & 0.6125 & 0.4874842 & 0 & 1 \\ \text { AGE } & 38.95478 & 14.63718 & 21 & 73 \\ \text { FAMILY } & 3.005 & 1.485845 & 1 & 12 \\ \text { UK } & 0.27 & 0.4442372 & 0 & 1 \\ \text { ALTPHOTO } & 0.5 & 0.5003128 & 0 & 1 \\ \text { OUT } & 0.805 & 0.3964486 & 0 & 1\end{array}$

Source: Own survey results. 


\section{Results}

Apart from the choice-experiments the questionnaire contained a number of attitudinal questions the results of some of which are presented here. The average number of visits to the British Museum (including the current visit) made by the respondents was 1.9 and the average visit lasted 1.7 hours. When asked what other sites they had thought about visiting that day instead of the British Museum the most frequently mentioned alternative was the Tower of London followed by the National Gallery, The Houses of Parliament, The Tate Gallery and the Tate Modern.

For the purposes of this study however, the most interesting results were the responses to the question of why individuals came to the British Museum. Only 0.8 percent stated that they had come because it was free. On the other hand of those individuals questioned on their way out of the museum with regards to what they most liked or disliked about the experience 14.9 percent mentioned that they disliked the crowds. Note that individuals were not shown a list of alternative likes or dislikes from which to select and nor were they shown a list of possible reasons for visiting the British Museum. The responses to the questions were unprompted.

The results of the choice-experiments, consistent with the theoretical model presented earlier, were analysed using the linear and log linear utility models. In this model the differences in the admission price (or difference in the log of income) were included along with the differences in the number of daily visitors. In order to permit the marginal valuation of costs imposed by additional visitors to change, the difference in the number of visitors squared was also included as a regressor. Other variables relating to the socio-economic characteristics of the respondent were also included in the analysis, but since these do not vary across choices they were introduced by interacting them with the number of visitors. Note that a variable was included the purpose of which was to determine whether the use of an alternative set of photographs exerted any influence on willingness to pay for reducing congestion. Another variable was included in order to determine whether the responses of individuals entering and exiting from the museum differed.

Table 3 details the results from both models. In either case the hypothesis of zero slopes is easily rejected. In both models the utility of income is significantly different from zero (much more so in the case of the linear utility function). The coefficients on both the linear and the quadratic terms of the number of visitors are statistically significant at the one-percent level in either model. Interestingly however, whilst the linear term is negative the quadratic term is positively signed. This suggests that although additional visitors reduce utility the rate of reduction is attenuated something that is seen, below, to have interesting and important implications. The only other variable that is significant is the variable that indicates whether the first or 
second set of photographs was used (but only in the logarithmic utility model) ${ }^{15}$. The variable indicating whether individuals were questioned on the way in or the way out is not significant and nor are any of the other socio-economic characteristics of individuals.

The two models are compared across the same sample of observations by examining the log likelihood. The linear utility model yields the highest log likelihood and this model is model used for analysis in the next section. Note finally that because each individual was asked to complete two choice-experiments the random errors between the two choice experiments completed by the same individual might not be independent of each other. The standard errors of the model have therefore been adjusted such that they are robust in the face of possible correlations of this kind.

${ }^{15}$ On one hand the significance of this variable might be quite reassuring since it means that individuals responded to the photographs that were shown to them. On the other hand it means that their evaluation of congestion costs depends upon the precise photograph that they were shown. 
Table 4: The Results of the Logit Regression

Variable

$\Delta$ (Log INCOME-PRICE)

$\triangle \mathrm{PRICE}$

$\Delta$ VISITORS

$\Delta\left(\right.$ VISITORS $\left.^{2}\right)$

DEGREE x $\Delta$ VISITORS

MALE x $\Delta$ VISITORS

AGE x $\Delta$ VISITORS

UK x $\Delta$ VISITORS

FAMILY x $\Delta$ VISITORS

ALTPHOTO x $\Delta$ VISITORS

OUT x $\Delta$ VISITORS

Number of Observations

Log Likelihood

$\chi^{2}$ Statistic (Zero Slopes)

Source: Own calculations.
Coefficient

(t-statistic)

423.4782

(2.049)

$-0.2946785$

$(-5.098)$

0.0077579

(5.923)

$-0.0150177$

$(-0.842)$

0.0141445

(1.029)

$-0.0002204$

$(-0.453)$

0.0240327

(1.524)

0.0058048

(1.223)

0.0393434

(2.691)

0.005123

(0.307)

738

$-440.96$

89.04
$-445.49$

116.90

Coefficient

(t-statistic)

0.1022392

(5.516)

$-0.1670302$

(-2.585)

0.0039815

(2.651)

$-0.0280741$

(-1.551)

.0186449

(1.356)

$-0.0006015$

$(-1.291)$

0.0193865

(1.239)

0.0074413

(1.516)

0.0263092

(1.833)

$-0.0025012$

(-0.146)

796 


\section{Discussion}

The results from the preceding section are now analysed in terms of what they imply about the congestion costs imposed by the marginal visit. The linear utility function is differentiated with respect to the number of visitors and divided by the derivative of the utility function with respect to income. The marginal utility of money however is not available. But the result of Hanemann (1984) can be invoked: when the indirect utility is a linear function the marginal utility of money is given by the coefficient on the price variable. The resulting expression is then evaluated at sample averages for the socio-economic characteristics and at 14,978 visitors (the daily average for 1999). Note that the variable describing whether the visitor was questioned before or after was set at the value 0.5 , as was the variable describing whether the first or second set of photographs was shown to the respondent. This means that the congestion costs that are calculated are effectively averaged over the different locations. Finally, the variable relating to the respondent's age was adjusted down to 35.6 years so as to reflect the congestion experienced by a visitor of average age as opposed to the average age of the respondents (all of whom were over 18).

The resulting figures give the individual's assessment of the congestion cost imposed by an additional visitor. This is estimated to be 0.04 pence. This figure is then multiplied by the number of visitors to obtain the aggregate congestion cost imposed by the marginal visitor on all other visitors $\frac{16}{16}$. The result is a congestion externality of $£ 5.99$ per person with a 95 percent confidence interval ranging from $£ 2.48$ to $£ 9.50$ 닌. There is however no necessary link between the marginal congestion cost and the optimal charge. The reason is that if a charge of $£ 5.99$ were to be imposed then the number of visitors would probably fall so that the congestion externality would change. This however does not mean that the optimal charge is necessarily less than $£ 5.99$. This is because the utility cost of the marginal visitor rises as the number of visits falls ${ }^{18}$. For example, if a charge of $£ 5.99$ were imposed and visitor numbers fell to say 12,000 per day then the value of excluding the marginal visitor would rise to 0.08 pence and the aggregate congestion externality would rise to $£ 7.58$.

The other issue that is likely to be of importance is the question of whether the visitors to the British Museum would actually benefit from a congestion charge. The possibility exists that, somewhat perversely, they may not. The reason is that whilst

\footnotetext{
${ }^{16}$ One person commenting on this paper asserted that the correct approach was to multiply by the number of individuals in the museum at any one moment. In fact however it is simple to demonstrate that changing the time period from visitors per day to visitors per any other time period and then multiplying by the number of visitors during that time period does not change the marginal congestion cost.

${ }^{17}$ This confidence interval is obtained using the delta technique.

18 The utility cost of the marginal visitor also becomes negative as the number of visitors is increased but this occurs at visitor numbers well in excess of those experienced in the busiest month.
} 
they may benefit from the exclusion of those individuals whose value for visiting the museum is less than the congestion costs that their presence entails, at the same time the remaining visitors all pay the congestion charge. This results in a potentially large transfer of revenue from the visitors to the museum that might exceed the benefits from eliminating the inefficiently high level of congestion. Hence, somewhat paradoxically, the visitors to the museum may be made worse off as a consequence of congestion charging (even if the benefits to society as a whole are positive)

19 Precisely the same issue arises in the context of road pricing. The gains from time savings enjoyed by remaining road users may be less than the losses borne by those priced off the road plus the charges paid to the charging authority. 


\section{Conclusions}

This paper has examined the relevance of a hitherto neglected argument in favour of charging for museums: the presence of significant congestion costs. Whilst the argument was developed in the context of the British Museum the same model could be applied to any museum or gallery or indeed other sites of cultural heritage.

The findings suggest that individuals do indeed consider the British Museum to be congested and would be prepared to pay something in order to reduce congestion and there is some weak evidence that these congestion costs do not appear to vary significantly with income levels. The implication is that there may be a significant loss of economic benefits by continuing to allow free admission - quite apart from all the other resource costs of admitting visitors. Such a view would however be premature until the main argument in favour of free (or more precisely subsidised) admission is properly explored - namely the idea that visits to museums confer some external benefit on the rest of society. When this interesting question is explored it will be important to know whether individuals view external benefits arising from the visits of British people and foreign people as well as the visits of children and adults differently. The other interesting finding is that the characteristics of individuals visiting the British Museum are such that there is quite a strong argument for charging on distributional grounds. 


\section{References}

Anderson, R. (1998) Is Charging Economic? Journal of Cultural Economics 22(2/3): 179-187.

Bailey, S. and Falconer, P. (1998) Charging for Admission to Museums and Galleries: A Framework for Analysing the Impact on Access. Journal of Cultural Economics 22(2/3): 167-177.

Beggs, S., Cardell, S. and Hausman, J. (1981) Assessing the Potential Demand for Electric Cars. Journal of Econometrics 16(1): 1-19.

Cannon-Brookes, P. (2001) The Place of Cultural Economic Analyses in the Management of Art Museums. Paper presented to a conference on Economics and Cultural Heritage in the University of Roma Tre in Rome on the 20th of February 2001.

Creigh-Tyte, S. and Selwood, S. (1998) Museums in the UK: some evidence on scale and activities. Journal of Cultural Economics Vol. 22(2/3): 151-165.

Forrest, D., Grime, K. and Woods, R. (2000) Is it Worth Subsidising Regional Repertory Theatre? Oxford Economic Papers 52: 381-397.

Frey, B. (1994) Cultural Economics and Museum Behaviour. Scottish Journal of Political Economy 41(3): 325-335.

Hanemann, M. (1984) Welfare Evaluations in Contingent Valuation Experiments with Discrete Responses. American Journal of Agricultural Economics 81(3): 635-647.

Johnson, P. and Thomas, B. (1998) The Economics of Museums: A Research Perspective. Journal of Cultural Economics 22(2/3): 75-85.

Martin, F. (1994) Determining the Size of Museum Subsidies. Journal of Cultural Economics 18(4): 255-270.

Newbery, D. (1992) Pricing and Congestion: Economic Principles Relevant to Pricing Roads. Oxford Review of Economic Policy 6(2): 22-37.

O'Hagan, J. (1995) National Museums: To Charge or not To Charge? Journal of Cultural Economics 19(1): 33-47.

Peacock, A. and Godfrey, C. (1974) The Economics of Museums and Galleries. The Lloyds Bank Review 111: 17-28. 
Robins, L. (1971) Unsettled Questions in the Political Economy of the Arts. The Three Banks Review 91: 3-19.

Sellar, C., Chavas, J. and Stoll, J. (1986) Specification of the Logit Model: The Case of Valuation of Nonmarket Goods. Journal of Environmental Economics and Management 13(4): 382-390. 